

Red de Investigadores Educativos Chihuahua A.C. Chihuahua, México www.rediech.org

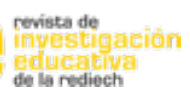

ISSN: 2007-4336

ISSN-e: 2448-8550

http://www.rediech.org/ojs/2017/index.php/ie rie rediech/index

Ismael García Cedillo

Bania Yarabí Hernández Hernández

Gabriela Silva Maceda

2019

\title{
NECESIDADES EDUCATIVAS ESPECIALES DEL ESTUDIANTADO INFANTIL Y JUVENIL QUE VIVE CON VIH
}

IE Revista de Investigación Educativa de la REDIECH, 10(19), pp. 121-138.

DOI: http://dx.doi.org/10.33010/ie_rie_rediech.v10i19.642

\section{(c) (1) (9)}

Esta obra está bajo licencia internacional

Creative Commons Reconocimiento-NoComercial 4.0.

CC BY-NC 4.0 


 INFIVTIL Y JIIEUIL QIIE IIIE CON IIII
}

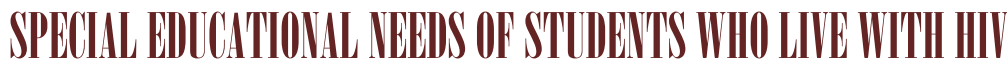

\author{
GARCÍA CEDILLO Ismael \\ HERNÁNDEZ HERNÁNDEZ Bania Yarabí \\ SILVA MACEDA Gabriela
}

Recepción: febrero 25 de 2019 | Aprobado para publicación: junio 23 de 2019

DOI: http://dx.doi.org/10.33010/ie_rie_rediech.v10i19.642

\section{Resumen}

Es importante que las escuelas tengan herramientas para identificar y satisfacer las necesidades educativas especiales (NEE) de algunos de sus estudiantes, especialmente de quienes pertenecen a grupos vulnerables, como los que viven con VIH, pues esta condición puede afectar su desarrollo cognitivo y, por tanto, su desempeño académico. El objetivo de la presente investigación fue identificar si los niños y adolescentes que viven con VIH presentan NEE y, de ser el caso, si las están atendiendo

Ismael García Cedillo. Profesor-investigador de tiempo completo en la Facultad de Psicología de la Universidad Autónoma de San Luis Potosí, México. Es doctor en Psicología Clínica por la Facultad de Psicología de la UNAM. Director del Proyecto Nacional de Integración Educativa (1998-2001). Entre sus publicaciones recientes tenemos "Algunas propiedades psicométricas de las guías para evaluar prácticas inclusivas en el aula" (2018) y "La educación inclusiva en la reforma educativa de México" (2018). Sus líneas de investigación son educación inclusiva, educación especial, NEE de alumnos con enfermedades crónicas y adherencia terapéutica en personas con enfermedades crónicas. Correo electrónico: garcia.ismae152@gmail.com. ID: http://orcid.org/0000-0002-4820-5633.

Bania Yarabí Hernández Hernández. Apoyare, Fundación García Cedillo AC., San Luis Potosí, México. Cuenta con estudios de Maestría en Psicología por el Instituto de Investigación y Posgrado de la Universidad Autónoma de San Luis P0tosí, educadora sexual por la Universidad Pedagógica Nacional y la Red de Diversificadores Sociales. Participa como tallerista en el Centro Nacional para la Prevención y el Control del VIH y el Sida. Colaboración en investigaciones con el Colegio de San Luis, como "Estudio sobre la situación actual de las mujeres en el embarazo, parto y puerperio en la microrregión Huasteca Centro”. Correo electrónico: bania.hhernandez@gmail.com. ID: http://orcid.org/00000002-2539-2958.

Gabriela Silva Maceda. Profesora-investigadora de tiempo completo de la Facultad de Psicología de la Universidad Autónoma de San Luis Potosí, México. Obtuvo su Doctorado en Psicología y su Postgraduate Diploma en la misma área en la Universidad de Wolverhampton, en Reino Unido. Cuenta además con una Licenciatura en Ciencias de la Comunicación del Tecnológico de Monterrey Campus Monterrey. Ha sido docente en educación superior en México y Reino Unido y maestra bilingüe de primaria en Garland, Texas, EUA. Cuenta con el perfil deseable Prodep y la distinción del Sistema Nacional de Investigadores Nivel Candidato. Correo electrónico: gabysilvamac@gmail.com. ID: http:// orcid.org/0000-0002-7313-4777. 
las escuelas. El presente estudio tiene un diseño mixto (cuantitativo y cualitativo), descriptivo y transversal. Participaron diez estudiantes de 6 a 14 años, además de sus cuidadores, el pediatra que los atiende y sus profesores. Se aplicaron ocho subpruebas de la escala Weschler de inteligencia para niños (WISC-IV) y entrevistas semiestructuradas a los niños y adolescentes, y entrevistas semiestructuradas al pediatra, los cuidadores primarios y los profesores de estos alumnos. Cinco de los participantes probablemente presentan NEE; estas se relacionan con su situación emocional y sus condiciones socioeconómicas. Algunos alumnos que viven con VIH pueden presentar NEE derivadas de la situación en que viven; las escuelas no parecen estar identificando ni satisfaciendo dichas necesidades, lo que pone en riesgo su trayectoria académica.

Palabras clave: NECESIDADES EDUCATIVAS ESPECIALES, VIH, INTEGRACIÓN EDUCATIVA, EDUCACIÓN INCLUSIVA.

\begin{abstract}
It is important that schools have the tools to identify and satisfy the Special Educational Needs (SEN) of some of their students, particularly those who belong to vulnerable groups, such as children living with HIV, since this condition can affect their cognitive development and their academic performance. The objective of this study was to identify whether children living with HIV have SEN, and if it was the case, identify whether their schools are trying to satisfy them. This study followed a mixed-methods design, descriptive and transversal approach. The participants were 10 school-age (ages six to 14) students, their caregivers, their pediatrician and their teachers. Semi-structured interviews were carried out with students, caregivers, pediatrician and teachers, and eight subtests of the Weschler Intelligence Scale for Children (WISC-IV) were used with the students. Five students living with HIV may present SEN not associated with the virus, but to their life conditions. Some children living with HIV may develop NEE related to their emotional situation and low socioeconomic status. Their schools are not trying to satisfy those special needs, as they don't identify them, which could in turn place them at an educational risk.
\end{abstract}

Keywords: SPECIAL EDUCATIONAL NEEDS, HIV, EDUCATIONAL INTEGRATION, INCLUSIVE EDUCATION.

\title{
IITRonicoiós
}

La infección por VIH constituye una condición de salud que hasta hace

122 algunos años era considerada mortal, pero, actualmente, con el uso de tratamientos 
antirretrovirales (TAR) ha evolucionado a ser considerada una enfermedad crónica. Por lo anterior, el impacto de la enfermedad es permanente, tanto en la vida de las familias como en la de los niños y adolescentes (NyA), quienes requieren de cuidados específicos y apoyos para realizar modificaciones en su estilo de vida. Actualmente, en México y en el resto del mundo el VIH y el sida no solo están presentes en la población adulta, sino también en los NyA, principalmente por la transmisión madre-hijo, que no se ha logrado erradicar (Nichols, 2013). Es necesario proporcionar a estos NyA una atención integral desde todas las perspectivas posibles, incluida la escolar (Usuga, 2012).

A nivel mundial, gracias al TAR aplicado a las madres se han evitado 1.4 millones de nuevas infecciones en niños. En 2017 solo hubo 180,000 infecciones de madre a hijo. La identificación del VIH en niños es muy complicada antes de los 18 meses de edad. De hecho, $50 \%$ de los niños sin tratamiento mueren antes de cumplir los dos años (UNAIDS, 2018).

Durante el periodo de 1986 a 2017 se reportaron en México un total de 201,570 casos notificados de personas con VIH, de los cuales 4,027 corresponden a niños y adolescentes de menos de uno a 14 años (CENSIDA, 2018). En el hospital donde se realizó el estudio se atiende a $30 \mathrm{NyA}$ (es el único lugar que da atención especializada en VIH pediátrico en el estado).

El virus de la inmunodeficiencia humana $(\mathrm{VIH})$ puede devenir en el síndrome de inmunodeficiencia adquirida (sida). Las principales vías de transmisión del virus son la sexual, sanguínea y vertical (materno-infantil). El riesgo de contagio existe solo si algunos fluidos (esperma, sangre, secreciones vaginales y leche materna) entran en contacto con ojos, boca, vagina, pene, ano y piel lacerada de otra persona (Vinaccia et al., 2007).

Actualmente, la mayor parte de la población infantil que vive con VIH se infectó por transmisión vertical, que puede acontecer en tres momentos distintos: 1) transmisión prenatal, intraútero o transplacentaria; 2) transmisión intraparto o perinatal; y, 3) transmisión posnatal o posparto (Morales, Vázquez y Suárez, 2007).

La infección por VIH tanto en pacientes adultos como en niños tiene como características la inmunosupresión provocada por la destrucción de los linfocitos CD4, así como un efecto patógeno directo o indirecto sobre otros órganos. Sin embargo, cuando la infección es muy temprana tiene mayor relevancia en el recién nacido y lactante al incidir el virus en la fase de ontogénesis y diferenciación (Aís y Martínez, 2005).

Para evaluar el estadio clínico de la infección en población infantil se usa un sistema de clasificación diferente hasta los 13 años; después, se usa la clasificación de adultos (Centers for Disease Control and Prevention, CDC, 1994). El estadio clínico se obtiene mediante un examen de laboratorio que mide la carga viral (la cantidad de partículas virales que hay en cada mililitro de sangre), lo cual permite clasificar a las personas infectadas en categorías que reflejen de forma más exacta sus manifestaciones clínicas y su pronóstico.

La infección por VIH es clasificada considerando el estado de la infección, la situación clínica y el compromiso inmunológico. Este sistema incluye categorías excluyentes, según las características clínicas presentadas. La situación inmunológica del niño se valora en función de su edad cronológica, quedando clasificada como: 
función inmune normal (1), inmunosupresión moderada (2) e inmunosupresión grave (3) (Conca y García, 2011; García, Romero y García, 2003), información que se muestra en la tabla 1.

Hay estudios que indican que los niños que viven con VIH, aun cuando reciben TAR, presentan alteraciones en el sistema nervioso central, que con frecuencia se reflejan en un déficit cognitivo, de lenguaje, motor y del comportamiento (Allison, Wolters y Brouwers, 2009; Castro et al., 2011; Colomé, 2015; Díaz-Barriga y Navarro, 2014; Muñoz, 2012 y Usuga, 2012).

La mayoría de la población infantil portadora del virus no solo es vulnerable por su condición de salud, sino además por su situación socioeconómica y sociocultural reflejada en carencias nutricionales, dificultad de asistencia a las citas médicas, insuficiente estimulación por parte de su familia y escasa oportunidad de acceder a una educación de calidad. En la mayoría de los casos, uno o ambos padres padecen la enfermedad, lo que aumenta la posibilidad de orfandad en el niño o la niña, quedando a resguardo de su familia extensa o de alguna institución gubernamental (Pérez-Cuevas et al., 2009).

Por lo anterior, los niños y las niñas que viven con VIH se sienten diferentes a sus pares no solo por las molestias, implicaciones y características físicas de una enfermedad crónica, sino también por el proceso adaptativo a su nueva condición de salud (Pavía-Ruz, Tovar-Larrea y Muñoz-Hernández, 2003). El contexto escolar es un espacio en el que se presenta claramente esta situación, ya que ahí pasan gran parte del día, socializan y expresan sus emociones (Argumosa y Herran, 2001). Además de lo anterior, en este espacio los NyA pueden enfrentar actitudes discriminatorias derivadas del desconocimiento y el tabú que existe alrededor de la enfermedad, situación que los coloca en una posición de vulnerabilidad para presentar necesidades educativas especiales (NEE).

El concepto de NEE surgió en el marco de la integración educativa; la Secretaría de Educación Pública (SEP) menciona que se refiere a los alumnos que, "en comparación con sus compañeros de grupo, tienen dificultades para el aprendizaje de los contenidos establecidos en el currículo" (SEP, 2002, p. 13), por lo cual requieren de apoyos específicos que deben proporcionarse para promover sus aprendizajes. En otras palabras, hay algunos niños que necesitan apoyos distintos a los que requieren los demás alumnos para que aprendan de acuerdo con su potencial. Las NEE se asocian a: características personales del alumno (como presentar una discapacidad 0 una enfermedad crónica), condiciones familiares y sociales (como sufrir abuso

Tabla 1. Categorías inmunológicas en pacientes pediátricos basadas en linfocitos CD4

\begin{tabular}{lcccccc}
\hline Categorías & \multicolumn{2}{c}{$<\mathbf{1 2}$ meses } & \multicolumn{2}{c}{ 1 a 5 años } & \multicolumn{2}{c}{ 6 a 12 años } \\
\cline { 2 - 7 } inmunológicas & Células/ml & $\mathbf{\%}$ & Células/ml & $\mathbf{\%}$ & Células/ml & $\mathbf{\%}$ \\
\hline $\begin{array}{c}\text { 1. Sin evidencia } \\
\text { de supresión }\end{array}$ & $\geq 1,500$ & $\geq 25$ & $\geq 1,000$ & $\geq 25$ & $\geq 500$ & $\geq 25$ \\
\hline $\begin{array}{c}\text { 2. Supresión } \\
\text { moderada }\end{array}$ & 750 a 1,499 & $\begin{array}{c}15 \text { a } \\
24\end{array}$ & 500 a 999 & $\begin{array}{c}15 \text { a } \\
24\end{array}$ & 200 a 499 & $\begin{array}{c}15 \mathrm{a} \\
24\end{array}$ \\
\hline $\begin{array}{c}\text { 3. Supresión } \\
\text { grave }\end{array}$ & $<750$ & $<15$ & $<500$ & $<15$ & $<200$ & $<15$ \\
\hline
\end{tabular}

Fuente: CDC (1994). 
físico o sexual) y condiciones áulicas (como estudiar en escuelas con muy escasos recursos o con maestros con poca formación) (García et al., 2000).

Las NEE pueden estar asociadas a una enfermedad crónica porque, al influir esta última en la alimentación, el sueño y en las habilidades motoras y sensoriales del niño, pueden llevarlo a presentar dificultades en su crecimiento y desarrollo emocional y cognitivo. Por otro lado, las hospitalizaciones frecuentes, las ausencias escolares y las limitaciones físicas impactan en la escolarización y en la socialización. Los niños con enfermedades crónicas, especialmente los niños que viven con VIH, tienen un alto riesgo de presentar problemas de comportamiento y fracaso escolar (Grau, 2003).

Las NEE en los niños que viven con VIH son diversas y poco predecibles, a diferencia de las que presentan niños con otras enfermedades crónicas. Estas NEE pueden ser de tres tipos:

1. Como consecuencia del diagnóstico y tratamiento. Se refieren a la adherencia al tratamiento, la asistencia a consultas médicas y exámenes de laboratorio y al conocimiento sobre la enfermedad por parte del niño, su familia y el entorno escolar (Grau y González, 2001).

2. Como consecuencia de los trastornos emocionales y sociales que se producen por la adaptación a la enfermedad. Se refieren a un amplio espectro de emociones de tipo negativo que puede experimentar el niño (y su familia); por ejemplo, ansiedad, enojo, culpa y aislamiento y conductas regresivas debidas a la falta de información, a la hospitalización constante, a las características propias de la enfermedad y a los tratamientos, etcétera (Grau y González, 2001; Lizasoáin, 2000).

3. Las relacionadas con el currículo escolar y la atención temprana para favorecer un adecuado desarrollo cognitivo, motor, afectivo y social del niño. Se refiere a la identificación de medidas que el entorno escolar puede tomar para atender las necesidades que tiene un niño con alguna enfermedad crónica; por ejemplo, flexibilidad en la asistencia a clases debido a la ausencia producida por la hospitalización, apoyo de los servicios de atención temprana, unidades escolares de apoyo en instituciones hospitalarias, atención educativa domiciliaria, etcétera (Grau y González, 2001).

En México, la identificación de las NEE de los alumnos que asisten a las escuelas regulares y su eventual satisfacción está a cargo de las Unidades de Servicios de Apoyo a la Educación Regular (USAER), equipos itinerantes conformados por personal de educación especial: un trabajador social, psicólogo, maestro de comunicación y maestros de apoyo; estas unidades ofrecen asistencia a los alumnos con NEE (al menos en teoría) mediante la orientación a los docentes regulares, a los padres de familia y, eventualmente, a los mismos NyA. En promedio, las USAER atienden de manera itinerante a cinco escuelas de educación básica por unidad, con excepción de los maestros de apoyo, que pueden permanecer en una escuela (Secretaría de Educación Pública, 2006).

Una de las dificultades que enfrentan los niños que viven con VIH tiene que ver con el desconocimiento de su condición por parte de sus profesores. Los padres y cuidadores se cuidan de comentar el diagnóstico a las escuelas, lo cual obedece al estigma y a la discriminación de que pueden ser objeto los NyA en los centros 
escolares e, incluso, en sus comunidades y familias (García y Juárez, 2010). Lo anterior explica por qué prácticamente no haya estudios en el país que muestren las posibles NEE de los niños que viven con VIH. Por otro lado, una alta cantidad de NyA desconocen su condición, entre otras razones porque sus padres o cuidadores primarios mantienen el diagnóstico en secreto, sea porque conocen muy poco acerca del VIH y no saben cómo decirlo, sea porque sienten culpa y vergüenza o bien por el temor de que los NyA difundan la información entre sus amigos (García, Viñas y Rodríguez, 2013).

Para evitar los efectos desgastantes de una enfermedad crónica hace falta una buena adherencia terapéutica. En el caso del VIH, la adherencia debe ser muy alta, pues se corre el riesgo de que se presenten mutaciones del virus. En los niños que viven con VIH, la adherencia tiende a ser baja, en parte por lo ya comentado (mantenimiento del secreto del diagnóstico por parte de padres o cuidadores primarios), además de su baja escolaridad, falta de apoyo familiar y comunitario y serias condiciones de pobreza (García y Juárez, 2014).

En resumen, los NyA que viven con VIH enfrentan situaciones muy difíciles en sus familias y comunidades. Es probable que en sus escuelas y aulas también enfrenten situaciones complicadas, independientemente de que sus maestros o compañeros puedan conocer su diagnóstico, pues el VIH podría disminuir su nivel de aprendizaje por afectar su cognición, porque pueden tener problemas emocionales o conductuales o por sus faltas contantes a clases, lo cual puede derivar en la aparición de las NEE. Por lo anterior, el objetivo general de esta investigación fue conocer si los niños y las niñas que viven con VIH en la capital de un estado del centro de México presentan NEE. Los objetivos específicos fueron: a) identificar las condiciones familiares, de salud y escolares que influyen en su rendimiento escolar; b) identificar las posibles NEE de los participantes.

\section{Ilínono}

Tipo de estunlio

El estudio es de tipo mixto, dado que tiene un enfoque cuantitativo (resultados de la escala de Wechsler y los cuestionarios), y un enfoque cualitativo (que se relaciona con la aplicación de entrevistas semiestructuradas). Es descriptivo porque detalla las dimensiones de la problemática y los factores asociados a ella. Se considera transversal porque se recolectaron datos en un solo momento, de campo, pues se realizó en escenarios naturales (Hernández, Fernández y Baptista, 2010).

\section{Pirticipintes}

La muestra se seleccionó de manera no probabilística, por conveniencia. Estuvo conformada por diez participantes de 7 a 14 años, 6 mujeres y 4 hombres (el total de NyA de estas edades atendidos en el hospital), estudiantes de educación básica provenientes de diferentes regiones de un estado del centro de México (véase tabla 2

126 que se presenta en la sección de resultados). Todos los participantes recibían atención 
médica en un hospital de segundo nivel, tenían diagnóstico de VIH y una carga viral indetectable al momento de la investigación.

Se trabajó con el médico y la enfermera que atienden a los niños en el hospital. Asimismo, se trabajó con las diez madres o cuidadoras primarias y sus respectivos NyA; además, se entrevistó a diez profesores en las escuelas a las que asistían los NyA.

\section{Instrinmentos}

Escala Wechsler de inteligencia para niños IV (WISC-IV) es un instrumento convencionalmente utilizado para evaluar la capacidad intelectual de NyA entre seis años cero meses hasta dieciséis años y once meses y cuenta con estandarización en la población mexicana. El trabajo de estandarización se realizó en el año 2005 con 1,234 participantes de zonas urbanas y suburbanas de diversos estratos sociales, de escuelas públicas y privadas. Está compuesta por diez subpruebas esenciales y cinco complementarias. En la presente investigación se aplicaron las subpruebas de diseño con cubos (DC), semejanzas (SE), vocabulario (VB), matrices (MT), aritmética (AR), claves (CL), búsqueda de símbolos (BS) y retención de dígitos (RD). Esto es, se aplicaron dos subpruebas de cada uno de los índices de la prueba: comprensión verbal (SE y VB), razonamiento perceptivo (DC y MT), memoria de trabajo (RD y AR) y velocidad de procesamiento (CL y BS). Cada una de las subpruebas tiene una media $=10$ y una desviación estándar $=3$ como valores normativos (Sánchez-Escobedo, 2006). Para el cálculo del coeficiente intelectual (CI) total se asignó como puntaje el promedio general a las subpruebas faltantes. ${ }^{1}$ El CI total tiene como valores normativos una media de 100 y una desviación estándar de 15 (Flanagan y Kaufman, 2012).

Entrevista semiestructurada para $N y A$. Se indagaron datos personales, familiares, escolares y de salud.

Entrevista semiestructurada para cuidadores primarios. Se indagaron datos personales, conocimiento de la enfermedad, expectativas escolares sobre el niño y recursos para la escolarización, así como información familiar general.

Entrevista semiestructurada para personal médico. Se indagó la condición clínica del participante, el tratamiento y sus efectos y la adherencia terapéutica.

Entrevista semiestructurada para los maestros de los NyA. Considerando que no era posible preguntar directamente por el rendimiento académico de los NyA de esta investigación, se hicieron preguntas generales acerca del grupo y preguntas más particulares con respecto a dos alumnos, uno de ellos participante del presente estudio (en los diez casos se procedió de esta manera, a pesar de que en la escuela se supiera el diagnóstico, pues este lo podía saber el director y no necesariamente los maestros).

\section{Rscentrilio}

Las entrevistas a los NyA, cuidadores y médico se realizaron en la clínica pediátrica de un hospital de segundo nivel ubicado en la capital de un estado ubicado en la región central de México, debido a que es el único lugar en el estado en que se ofrece atención médica a esta población. A los maestros se les entrevistó en sus respectivas escuelas y aulas. 


\section{Procedimiento}

Una vez obtenida la autorización por el Departamento de Enseñanza e Investigación del hospital se realizó el contacto con el médico encargado de la atención en la clínica pediátrica, quien facilitó el contacto con los cuidadores primarios de los NyA que acudían a consulta médica. Se presentó a los cuidadores el proyecto y, una vez firmado el consentimiento informado, se realización las entrevistas al médico pediatra, a los cuidadores y a los NyA (a ellos se evitó mencionar el diagnóstico). A estos últimos también se les aplicaron las ocho subpruebas de WISC-IV. Finalmente, se hizo la entrevista a los maestros de los NyA y se revisaron los expedientes para registrar los valores de los linfocitos CD4 y de la carga viral.

\section{C'onsideraciones éticiass}

El presente trabajó cumplió con las normas para la investigación en salud establecidas por la Convención de Helsinki (Asociación Médica Mundial, 2017). El estudio se clasifica como una investigación sin riesgo, ya que no se hizo intervención con la población, se garantizó la confidencialidad de la información para evitar la identificación de los participantes mediante el consentimiento informado y se obtuvo el permiso institucional para la realización del proyecto.

\section{Resillitinas}

A continuación, se presentan, en la tabla 2, las principales características de los NyA. Son cuatro hombres y seis mujeres, con una media de edad de 10.2 años.

El primer objetivo específico de esta investigación fue identificar las condiciones familiares, de salud y escolares que influyen en el rendimiento escolar de los NyA que conformaron la muestra. Las entrevistas con las cuidadoras mostraron lo que se puede observar en la tabla 3. Con respecto a su condición familiar, siete de los participantes son huérfanos de padre, madre 0 ambos, quienes fallecieron a causa del VIH/

Tabla 2. Características de los NyA participantes

\begin{tabular}{lccc}
\hline Sujeto & Sexo & Edad & Grado escolar \\
\hline 1 & $\mathrm{~F}$ & 6 & $1^{\circ}$ de primaria \\
\hline 2 & $\mathrm{~F}$ & 7 & $2^{\circ}$ de primaria \\
\hline 3 & $\mathrm{M}$ & 10 & $5^{\circ}$ de primaria \\
\hline 4 & $\mathrm{~F}$ & 10 & $5^{\circ}$ de primaria \\
\hline 5 & $\mathrm{M}$ & 10 & $5^{\circ}$ de primaria \\
\hline 6 & $\mathrm{M}$ & 10 & $4^{\circ}$ de primaria \\
\hline 7 & $\mathrm{M}$ & 10 & $5^{\circ}$ de primaria \\
\hline 8 & $\mathrm{~F}$ & 11 & $5^{\circ}$ de primaria \\
\hline 9 & $\mathrm{~F}$ & 14 & $1^{\circ}$ de secundaria \\
\hline 10 & $\mathrm{~F}$ & 14 & $2^{\circ}$ de secundaria \\
\hline Fuente: Elaboración propia. & &
\end{tabular}


sida, razón por la cual los NyA viven con algún miembro restante de su familia, en casa-hogar o con su familia extensa. Tres participantes viven con su familia nuclear.

En todos los casos, las cuidadoras primarias son mujeres y la mayoría tiene baja escolaridad: dos son analfabetas, siete cuentan con algún grado de escolaridad básica y una tiene una carrera técnica en enfermería. Ocho cuidadoras se dedican al hogar y dos son empleadas. De acuerdo con la información socioeconómica, ocho familias pertenecen al nivel $\mathrm{E}$ (segmento de la población con la menor calidad de vida y bienestar, por lo que carece de servicios y bienes), una familia al nivel D (familias que tienen cubierta la infraestructura mínima sanitaria de su hogar) y una al nivel C (se caracteriza por haber alcanzado un nivel de vida que resulta práctica y les permite ciertas comodidades, con infraestructura básica en entretenimiento y tecnología), de acuerdo a la clasificación de la Asociación Mexicana de Agencias de Investigación (Asociación Mexicana de Agencias de Inteligencia, AMAI, s.f.; López, 2011).

Un problema de los NyA se relaciona con su escasa socialización. Frente a ello, las cuidadoras intentan socializarlos, pero el temor de que la escuela conozca el diagnóstico ha llevado a algunas a mentir sobre lo que los NyA pueden o no hacer, como lo expresa una cuidadora: "Yo le dije a la maestra que el niño tenía una enfermedad rara y que no podía salir al sol ni correr mucho; entonces, en el recreo casi no juega, ni en educación física lo juntan porque se supone que no puede correr mucho".

Se identificaron bajas expectativas de las cuidadoras con respecto al logro escolar de los NyA. Dos cuidadoras esperan que solamente concluyan la educación primaria, cuatro la secundaria y el resto la preparatoria (las carreras técnicas equivalen a la preparatoria). Considerando esto, en siete casos las cuidadoras esperan que los NyA a su cargo alcancen el mismo nivel educativo que ellas alcanzaron). Por ejemplo, una de las cuidadoras mencionó lo siguiente: "Yo no sé cuánto va a vivir, así que no sé hasta cuánto va a estudiar; hasta donde él quiera está bien". Otra cuidadora dijo: "Pues si de pedir se trata, a mí me gustaría que hiciera una carrera, aunque fuera técnica, pero, pues, no sé, con que haga la prepa está bien". La cuidadora de mayor escolaridad dijo: "Yo voy a hacer todo lo posible porque termine por lo menos la

\begin{tabular}{lllllll}
\hline \multicolumn{7}{c}{ Tabla 3. Características de las cuidadoras primarias } \\
\hline Particip. & $\begin{array}{l}\text { Tipo de } \\
\text { familia }\end{array}$ & $\begin{array}{l}\text { Cuidador } \\
\text { primario }\end{array}$ & $\begin{array}{l}\text { Escolaridad } \\
\text { del cuidador }\end{array}$ & $\begin{array}{l}\text { Ocupación } \\
\text { cuidador }\end{array}$ & Expectativas & NSE* \\
\hline 1 & Sustitutiva & Abuela & Ninguna & Ama de casa & Secundaria & E \\
\hline 2 & Casa-hogar & Instructora & Técnica & $\begin{array}{l}\text { Empleada de } \\
\text { gobierno }\end{array}$ & Preparatoria & D \\
\hline 3 & Sustitutiva & Abuela & Ninguna & Ama de casa & Secundaria & E \\
\hline 4 & Sustitutiva & Tía & Primaria & Ama de casa & Primaria & E \\
\hline 5 & Sustitutiva & Abuela & $4^{\circ}$ primaria & Ama de casa & Secundaria & E \\
\hline 6 & Nuclear & Madre & Primaria & Ama de casa & Primaria & E \\
\hline 7 & Nuclear & Madre & Secundaria & Empleada & Secundaria & E \\
\hline 8 & Sustitutiva & Tía abuela & Carrera técnica & Ama de casa & Preparatoria & C \\
\hline 9 & Sustitutiva & Tía & Preparatoria & Ama de casa & Preparatoria & E \\
\hline 10 & Nuclear & Mamá & Secundaria & Empleada & Secundaria & E \\
\hline
\end{tabular}

* NSE: nivel socioeconómico. E: se carece de servicios y bienes. D: cobertura mínima de infraestructura sanitaria. C: infraestructura básica en entretenimiento y tecnología.

Fuente: Elaboración propia. 
preparatoria, porque creo que puede". Se podrá observar que, en la mayoría de los casos, las condiciones socioeconómicas no favorecen el estudio a los NyA, pues para las cuidadoras, las prioridades giran en torno a la alimentación y a conseguir los servicios básicos.

Las entrevistas con el médico y la revisión de expedientes mostraron lo descrito en los siguientes párrafos.

Todos los participantes adquirieron el VIH de forma vertical durante el embarazo, el parto o la lactancia. En ocho participantes, el diagnóstico se realizó posterior a los tres años de edad como consecuencia de una infección oportunista, y en dos antes de los tres años, lo cual refleja las dificultades de esta población para acceder a los servicios de salud.

Los reportes de laboratorio de los NyA muestran cargas virales indetectables, por lo cual se considera como bueno su estado clínico. Al momento del estudio, el tratamiento antirretroviral prescrito a los NyA estaba conformado por tres medicamentos distintos al día en presentación de jarabe o tabletas, con una consulta médica cada bimestre en la cual se evalúa la reacción al tratamiento mediante la revisión de los efectos secundarios y la replicación viral. Al respecto, el médico comenta: "Voy viendo la combinación de medicamentos que más se ajusta a los niños, si mejoran, si no les ocasionan problemas gástricos, en fin, para que se los quieran seguir tomando". Como resultado de ello, actualmente todos los participantes reportan nulos efectos secundarios al tratamiento.

En cinco casos los participantes conocieron su diagnóstico por medio de una psicóloga que trabajaba como voluntaria en el hospital, acompañada por la cuidadora primaria. En otro caso el participante se enteró por medio de comentarios de las maestras quienes, a su vez, se enteraron por medio del chofer del transporte del sistema municipal que trasladaba a los NyA de su comunidad al hospital. Al respecto, el participante aludido comentó: "A mí me sentaron en una mesa aparte en el desayuno y me dieron un vaso y un plato desechable; me dijeron que porque tenía sida".

En relación con las entrevistas a los NyA se encontró que, en general, reportan el deseo de tener un círculo más extenso de amistades, como lo refiere un participante: "En la escuela no tengo muchos amigos; ellos me ven raro". En otros casos el distanciamiento ocurre por las agresiones verbales, como comenta otra participante: "Yo solo tengo amigos, no amigas, porque ellas me dicen que estoy fea, y yo me enojo y las golpeo".

En relación con el segundo objetivo específico, consistente en identificar las posibles NEE de los participantes, se encontraron los siguientes resultados.

Entrevistas realizadas a los maestros (ver tabla 4).

En cinco de las escuelas se conoce el diagnóstico y en las cinco restantes solo se sabe que los participantes tienen una enfermedad, pero no el diagnóstico.

En relación con su trayectoria escolar, dos participantes han repetido algún ciclo escolar. Por otro lado, cuando un participante no asiste a clases, generalmente la estrategia de recuperación de conocimientos es pedirle las notas a algún compañero; aparentemente, los maestros no dan apoyo a los NyA para que recuperen los contenidos escolares. Como dice un participante: "Cuando vengo a consulta y no voy a 130 la escuela, la maestra me dice que solo pida la tarea con un compañero y se la lleve 
al día siguiente, y ya". A dos participantes los cambiaron de escuela. En un caso, la causa fue que se presentaron problemas de discriminación al conocer su diagnóstico.

En relación con sus calificaciones, cinco alumnos parecen tener dificultades en cuanto a su aprovechamiento académico (promedio de 7 o menos). Llama la atención la aparente independencia de las variables CI total y promedio de calificaciones, pues el alumno con el segundo menor puntaje en CI obtiene la calificación más alta.

El CI global de los participantes, en promedio, fue bajo, a más de una desviación estándar, con excepción de los participantes 8 y 10. De hecho, cinco de los participantes obtuvieron un puntaje de CI total a dos o más desviaciones estándar por debajo de la media.

En relación con las condiciones escolares, en cuatro NyA participantes se identificaron problemas de socialización derivados en algunos casos por la percepción de ser distintos a sus pares, principalmente porque directivos y maestros los segregan, aunque no necesariamente por su diagnóstico médico (puede ser por conducta considerada como inapropiada o por un pobre rendimiento escolar).

Finalmente, se podrá apreciar que, en cuanto al ambiente alfabetizador en el hogar, los estímulos son escasos, pues, por ejemplo, en cuanto al acceso a material de lectura adicional al proporcionado en la escuela, en seis casos no cuentan en sus casas con libros distintos a los que da la escuela.

Sobre los resultados de las subpruebas aplicadas de WISC-IV, se encontró que los participantes (con excepción del 3 y el 8) obtuvieron puntuaciones con más de una desviación estándar por debajo de la media en ambas subpruebas de la escala verbal (vocabulario y semejanzas). El compuesto verbal (SE y VB) obtuvo el menor puntaje, seguido del compuesto memoria de trabajo (RD y AR); ambos compuestos están relacionados con el rendimiento escolar (Gabinete Psicodiagnosis, 2019). El compuesto velocidad de procesamiento (CL y BS) obtuvo el puntaje menos bajo, como se muestra en la tabla 5. A nivel de subpruebas, todos los puntajes promedio del grupo estuvieron a más de una desviación por debajo del promedio, con excepción de claves, que tuvo un promedio de 8.

\begin{tabular}{ccccccc}
\hline \multicolumn{5}{c}{ Tabla 4. Características escolares derivadas de las entrevistas a los maestros } \\
\hline Particip. & $\begin{array}{c}\text { Promedio } \\
\text { escolar }\end{array}$ & $\begin{array}{c}\text { CI } \\
\text { WISC- } \\
\text { IV }\end{array}$ & $\begin{array}{c}\text { Escuela } \\
\text { conoce Dx }\end{array}$ & $\begin{array}{c}\text { Repetición } \\
\text { de año }\end{array}$ & $\begin{array}{c}\text { Quejas por } \\
\text { conducta }\end{array}$ & $\begin{array}{c}\text { Acceso } \\
\text { a libros }\end{array}$ \\
\hline 1 & 8.0 & 76 & Sí & No & No & No \\
\hline 2 & 8.0 & 72 & Sí & No & No & Sí \\
\hline 3 & 7.0 & 77 & Sí & No & No & Sí \\
\hline 4 & 9.0 & 60 & Sí & No & Sí & No \\
\hline 5 & 8.7 & 68 & No & No & No & No \\
\hline 6 & 6.0 & 68 & No & Sí & No & Sí \\
\hline 7 & 6.5 & 70 & No & No & Sí & No \\
\hline 8 & 8.2 & 89 & No & No & Sí & No \\
\hline 9 & 6.0 & 58 & Sí & Sí & Sí & Sí \\
\hline 10 & 7.0 & 86 & No & No & No & No \\
\hline
\end{tabular}

Fuente: Elaboración propia. 


\begin{tabular}{ccccccccc}
\hline \multicolumn{7}{c}{ Tabla 5. Puntuaciones escalares WISC-IV } \\
\hline Particip. & SE & VB & DC & MT & RD & AR & CL & BS \\
\hline 1 & 2 & 6 & 8 & 7 & 6 & 8 & 9 & 7 \\
\hline 2 & 3 & 3 & 6 & 7 & 4 & 4 & 15 & 6 \\
\hline 3 & 6 & 9 & 6 & 6 & 7 & 6 & 7 & 7 \\
\hline 4 & 3 & 6 & 8 & 5 & 8 & 11 & 6 & 7 \\
\hline 5 & 4 & 5 & 6 & 5 & 5 & 5 & 6 & 7 \\
\hline 6 & 6 & 5 & 8 & 10 & 7 & 3 & 1 & 5 \\
\hline 7 & 1 & 6 & 1 & 4 & 12 & 1 & 6 & 5 \\
\hline 8 & 8 & 7 & 7 & 8 & 7 & 8 & 11 & 10 \\
\hline 9 & 5 & 5 & 3 & 5 & 5 & 6 & 9 & 1 \\
\hline 10 & 5 & 4 & 13 & 9 & 8 & 8 & 10 & 12 \\
\hline Promedio & $\mathbf{4 . 3}$ & $\mathbf{5 . 6}$ & $\mathbf{6 . 6}$ & $\mathbf{6 . 6}$ & $\mathbf{6 . 9}$ & $\mathbf{6 . 0}$ & $\mathbf{8 . 0}$ & $\mathbf{6 . 7}$ \\
\hline
\end{tabular}

Nota: SE: semejanzas; VB: vocabulario; DC: diseño con cubos; MT: matrices; RD: retención de dígitos; AR: aritmética; CL: claves; BS: búsqueda de símbolos.

Fuente: Elaboración propia.

\section{Disctisiói}

El objetivo general de esta investigación fue conocer si los niños y las niñas que viven con VIH en la capital de un estado del centro de México presentan NEE. El primer objetivo específico fue determinar las condiciones familiares, de salud y escolares que influyen en el rendimiento escolar de los NyA participantes en el estudio.

Entre los resultados, se encontró que los NyA que viven con VIH enfrentan distintas situaciones que probablemente inciden de manera negativa en su rendimiento escolar. En primer lugar, la mayoría vive con familias sustitutas o extensas. Sin duda, esta situación puede afectar seriamente su estabilidad emocional, pues no solamente han atestiguado la muerte de alguno de sus padres, sino que viven con personas ajenas a su núcleo familiar. Al respecto, Pavía-Ruz et al. (2003) refieren que la pérdida de alguna persona significativa, en el caso de los niños, niñas y adolescentes que viven con VIH, no solo los confronta con el duelo, sino que los coloca frente a la posibilidad de perder su propia vida y con el secreto sobre la razón de la muerte al tratarse de un tema que continúa produciendo estigma social.

En segundo lugar, sus cuidadoras tienen un nivel socioeconómico muy precario (solamente una madre tiene un nivel de cierto desahogo). En general, los estudios sobre los factores asociados al rendimiento académico muestran que una de las principales variables que lo determinan es el nivel socioeconómico, pues las familias están más preocupadas por la supervivencia que por otras cuestiones (Cervini, 2002; Gil, 2013; Hernández y González, 2011; Jiménez, 1988; Peña, 2002; Sentín, 2001). Labin y Taborda (2014) encontraron una fuerte relación entre el bajo nivel académico de las madres y el puntaje en el compuesto verbal del WISC IV obtenido por sus hijos, que en el presente estudio obtuvo el promedio más bajo.

En tercer lugar, y muy relacionado con lo anterior, las expectativas de las cui132 dadoras con respecto a la trayectoria académica de los NyA son sumamente bajas. 
Solamente en tres casos hay la expectativa de que los NyA estudien la preparatoria. Además, en cuanto a tener mayores oportunidades de aprendizajes académicos, se debe considerar que la mayoría solamente tiene acceso a material de lectura proporcionado en la escuela: en seis casos no cuentan en sus casas con libros distintos a los que da la institución educativa.

Hay estudios que indican que las expectativas de los familiares determinan en buena medida la trayectoria académica de los NyA. Por ejemplo, Bravo et al. (2017) encontraron en Chile que las expectativas altas de la familia hacen la diferencia en el rendimiento académico de los hijos. Esto coincide con los resultados encontrados por el Tercer Estudio Regional Comparativo y Explicativo (Laboratorio Latinoamericano de Evaluación de la Calidad de la Educación, 2015), en el cual se señala que el desempeño académico se encuentra influido por los antecedentes escolares, las prácticas educativas en el hogar y las características socioeconómicas, demográficas y culturales que tienen las familias. Por su parte, Chaparro, González y Caso (2016) encontraron que el bajo nivel socioeconómico, escaso capital cultural y poco involucramiento de las familias con los estudiantes estaban asociados con un pobre rendimiento académico.

Por otro lado, al parecer los NyA de este estudio presentan algunos problemas de socialización. El temor al estigma y discriminación por parte de sus pares parece propiciar que estos NyA se aíslen, e incluso que algunos NyA reaccionen con violencia hacia algunos de sus compañeros. De hecho, cuidadoras, NyA y el médico coincidieron en señalar estas dificultades de socialización.

En relación con el segundo objetivo específico, identificar las posibles NEE de los participantes, se encontró que, por razones de confidencialidad y para evitar el estigma y la discriminación, en la mitad de las escuelas desconocen su diagnóstico. Esta situación, al tiempo que los protege, impide que sus maestros tomen en cuenta que sus inasistencias y tal vez algunos problemas emocionales los llevan a requerir apoyos específicos, los cuales no están recibiendo (los maestros les piden que, cuando falten, simplemente pidan los apuntes a sus compañeros).

Por otro lado, cinco alumnos están obteniendo calificaciones bajas ( 7 o menos) $\mathrm{y}$, en general, las calificaciones no parecen tener relación con su CI total. De hecho, llaman la atención los puntajes tan bajos de los alumnos en cuanto a su CI total; esto es, ocho NyA alcanzaron un puntaje considerado como punto débil (más de dos desviaciones estándar) (Gabinete Psicodiagnosis, 2019).

Una posible hipótesis para los resultados tan bajos en cuanto al CI total es que simplemente así son los alumnos. Sin embargo, sus calificaciones no corresponden a esta hipótesis, pues cinco NyA logran calificaciones de ocho o mayores.

Una segunda hipótesis indicaría que tal vez el virus está provocando serios problemas cognitivos en los participantes. Esta hipótesis no parece muy robusta, por el estatus de "indetectable" en la carga viral actual de los NyA; esto es, al menos en la actualidad tienen una buena adherencia terapéutica.

Otra hipótesis indicaría que estos NyA han desarrollado serios problemas emocionales, lo cual se evidencia en los puntajes tan bajos en las subpruebas. Además, se tiene el dato de que cuatro participantes tienen problemas de socialización y enfrentan medidas discriminatorias por parte de sus maestros, sin que aparentemente 
estas medidas tengan que ver directamente con su seropositividad. Dos participantes han repetido año y a dos participantes los han tenido que cambiar de escuela.

Al parecer, hay dos situaciones que repercuten de manera determinante en los posibles problemas emocionales de los participantes: por un lado, tres participantes viven con su abuela, tres con una tía y una con una cuidadora ajena a la familia. Haber atestiguado la muerte de alguno de sus padres, quedar huérfanos y vivir con familiares puede ser una experiencia muy dañina. Incluso los tres participantes que viven con sus madres (sin sus padres varones) deben enfrentar condiciones difíciles por la seropositividad de estas.

La segunda situación compleja que viven los NyA se relaciona con el hecho de saberse distintos de los demás, saber que tienen que llevar un régimen medicamentoso que sus compañeros de escuela no llevan, tener la idea de que tienen una condición que los mantendrá medicados el resto de sus días e incluso vivir todo lo anterior sin entender bien por qué.

Lo anterior coincide con lo señalado por Pérez-Cuevas et al. (2009, p. 365), quienes concluyen, en un estudio realizado en el Hospital Infantil de México, que "los niños y adolescentes que viven con VIH y sus familias tenían severas condiciones de vulnerabilidad social y escasa posibilidad para desarrollar competencias educativas y laborales".

Las condiciones escolares tienen un impacto significativo en el rendimiento académico de los niños y las niñas. Con alguna excepción, el desarrollo escolar no es prioridad para los cuidadores, y las faltas sistemáticas a clases hacen que en la escuela se especule sobre las posibles razones de su ausencia y, a su vez, dificultan el establecimiento de lazos entre sus iguales; por lo anterior, el sentimiento de diferencia se exacerba y la ausencia de lazos de amistad tiene como consecuencia dificultades para relacionarse adecuadamente con sus compañeros y compañeras de grupo, así como con los profesores. Al respecto, Pavía-Ruz et al. (2003), en sus investigaciones, han encontrado un alto porcentaje de adolescentes en los que se observa trastorno depresivo, ansiedad, bajo rendimiento escolar y en algunos casos ideación suicida (Conca y García, 2011). ${ }^{2}$

Por otro lado, es necesario tomar en cuenta al ausentismo como una vía de investigación, pues pudiera estar relacionado con el bajo rendimiento escolar. Las investigaciones de gran escala sugieren que el ausentismo escolar es un factor crítico relacionado con el desempeño escolar en la población estudiantil en general (Morrissey, Hutchison y Winsler, 2013).

Todos los participantes enfrentan condiciones de vida difíciles: vivir con familias ajenas a la nuclear o en la familia nuclear uniparental con una madre con VIH, familias con serios estresores económicos, baja escolaridad de madres o cuidadoras, conocimiento parcial o desconocimiento de su diagnóstico, bajas expectativas con respecto a su trayectoria académica, escuelas que en ocasiones no conocen su diagnóstico, repetición de grados escolares, reportes de problemas de conducta, ausencia de oportunidades de aprendizajes académicos y muy bajos puntajes en los subpruebas y el CI de la escala de Wechsler. Por esta razón, solamente se tomó en cuenta la calificación (de 70 menos en promedio) para identificar a los participantes con 134 NEE, de los cuales cinco de ellos probablemente las presentan. Con esos promedios 
es muy difícil que logren una trayectoria escolar exitosa, pues necesitarían apoyos muy específicos para que logren un rendimiento académico más favorable que difícilmente obtendrán (como se mencionó, en cinco casos sus escuelas ni siquiera conocen su diagnóstico).

Estos hallazgos coinciden en general con los reportados en el trabajo de Martínez y Ercikan (2008), quienes mencionan que los niños con enfermedades crónicas tienen el doble de prevalencia de problemas escolares y psicológicos. Estos autores encontraron que, en una muestra muy amplia de niños con enfermedades crónicas en Canadá (1,512, de edades entre 10 y 15 años), incluso controlando los puntajes de la escala de problemas emocionales y de ansiedad y de desventajas educativas, los niños con enfermedades crónicas todavía obtienen un pobre rendimiento en ejercicios de matemáticas.

La mitad de los participantes conoce de manera muy parcial su diagnóstico y la otra mitad lo desconoce. Pavía-Ruz et al. (2003) señalan que la falta de información puede conducir a NyA a desarrollar fantasías erróneas sobre su enfermedad, mientras que quienes sílo conocen tienen mayor autoestima y experimentan menos depresión en comparación con quienes lo desconocen.

Un aspecto muy positivo encontrado en la presente investigación es que, en general, los participantes reportan un estado clínico bueno. La salud de los NyA se debe a la alta adherencia al tratamiento, que implica la asistencia constante a sus citas médicas; esta situación se corrobora por los estudios de cargas virales indetectables, lo que podría indicar que el VIH no está afectando directamente su salud y, por lo tanto, tampoco su rendimiento académico. Es decir, que las posibles NEE tienen relación más con otros factores sociales (como el temor a la discriminación y al estigma) que con el virus.

Se deben tomar los resultados de este estudio con precaución, pues la muestra fue muy reducida y las condiciones de aplicación no fueron óptimas. Como se mencionó, la escala de WISC se tuvo que aplicar incompleta por el cansancio que mostraban los participantes. Las madres o cuidadoras también mostraron cansancio. En las escuelas no pudo entrevistarse a los docentes de manera más completa y directa por cuestiones de confidencialidad.

\section{Conculsiones}

Los logros académicos están relacionados no solo con la capacidad del sujeto para aprender, sino que el medio escolar y el entorno familiar influyen de manera en ocasiones determinante. En el presente estudio se concluye que la mitad de los NyA (especialmente los que tienen mayor edad) que viven con VIH tienen mayores probabilidades de presentar NEE, pero no parecen estar determinadas por su condición de salud, sino por los problemas emocionales provocados por los distintos estresores que enfrentan: vivir con familias ajenas a la nuclear o en la nuclear pero incompleta por la ausencia o fallecimiento del padre, carencias económicas, temor por una condición de salud que no conocen ni comprenden y por la falta de apoyo de sus escuelas, entre otros. 
La cronicidad que se ha logrado en la enfermedad debe ir de la mano, también, de una mejor calidad de vida, de ahí que se enfatice la necesidad de programas integrales para atender de manera oportuna a esta población y favorecer no solo la obtención de tratamiento antirretroviral, sino también acompañar sus procesos educativos, para así garantizar una trayectoria escolar de éxito.

\section{Referencitiss}

Aís, A. y Fernández-Llamazares, C.M. (s/f): Infección VIH en pediatría. Recuperado de https:// www.sefh.es/bibliotecavirtual/casosvih/CASO6 PEDIATRIA.pdf

Allison, S., Wolters, P. y Brouwers, P. (2009). Youth with HIV/AIDS: Neurobehavioral consequences, 187-211. Humana Press. https://dx.doi.org/10.1007/978-1-59745-434-6_9

Argumosa, A. y Herrán, J.L. (2001). Necesidades educativas especiales derivadas de problemas crónicos de salud. Boletín de Pediatría, (41), 23-29.

Asociación Médica Mundial. (2017). Declaración de Helsinski de la AMM. Principios éticos para las investigaciones médicas en seres humanos (revisada el 5 de mayo de 2015). Recuperado de https://www.wma.net/es/policies-post/declaracion-de-helsinki-de-la-amm-principioseticos-para-las-investigaciones-medicas-en-seres-humanos/

Asociación Mexicana de Agencias de Inteligencia. (s.f.). ¿Qué es NSE? Recuperado de http://nse. amai.org/nse/

Bravo, M., Salvo, S., Mieres, M., Mansilla, J. y Hederich, C. (2017). Perfiles de desempeño académico: la importancia de las expectativas familiares. Perfiles Latinoamericanos, 25(50), 361-386. https://dx.doi.org/10.18504/p12550-016-2017

Castro, M., Martínez, Y., González, I., Velásquez, J., Castillo, G., y Sánchez, L. (2011). Evaluación neuropsicológica, factores psicosociales y co-morbilidad psiquiátrica en pacientes pediátricos infectados con el VIH. Revista Chilena de Infectología, 28(3), 248-254.

CDC. (1994). Revised classification system for HIV infection and expanded surveillance case definition for AIDS among adolescents and adults (MMWR 1994, 43, n. RR-12, pp. 1-10). Recuperado de https://www.cdc.gov/mmwr/preview/mmwrhtml/00032890.htm

Censida. (2018). Boletín epidemiológico a tercer semestre de 2018. Recuperado de https:// www.gob.mx/cms/uploads/attachment/file/413909/BOLETIN_EPIDEMIOLOG_A_3ER_ TRIMESTRE_2018_1.pdf

Cervini, R. (2002). Desigualdades en el logro académico y reproducción cultural en Argentina. Revista Mexicana de Investigación Educativa, 7(16), 445-500. Recuperado de http://www. redalyc.org/pdf/140/14001604.pdf

Chaparro, A., González, C. y Caso, J. (2016). Familia y rendimiento académico: configuración de perfiles estudiantiles en secundaria. Revista Electrónica de Investigación Educativa, 18(1), 53-68. Recuperado de http://redie.uabc.mx/redie/article/view/774

Colomé, R. (2015). Perfil neuropsicológico a los 6-8 años de niños sanos, hijos de madres con infección por el VIH o por el VHC (tesis doctoral no publicada). Universidad Autónoma de Barcelona, Barcelona, España.

Conca, B. y García, R. (2011). Neuropsicología de niños infectados verticalmente por el virus de inmunodeficiencia humana. Revista Chilena de Psiquiatría y Neurología de la Infancia y Adolescencia, 22(1). Recuperado de https://www.sopnia.com/boletines/Revista\%20 SOPNIA\%202011-1.pdf

Díaz-Barriga, A. y Navarro, M.E. (2014). Características neuropsicológicas de una población pediátrica con VIH. Neuropsiquiatría y Neurociencias, 14(3), 1-17.

Flanagan, D. y Kaufman, A. (2012). Claves para la evaluación con WISC IV (2 ed.). México: Manual Moderno. 
Gabinete Psicodiagnosis. (2019). Interpretación del WISC IV. Recuperado de https:// psicodiagnosis.es/areaespecializada/instrumentosdeevaluacion/interpretaciondelwisciv/index. php

García, A., Romero, J. y García, M. (2003). La infección por el VIH: guía práctica (cap. 45, pp. 541-568). España: Sociedad Andaluza de Enfermedades Infecciosas. Recuperado de http:// www.saei.org/documentos/biblioteca/pdf-biblioteca-11.pdf

García, I., Escalante, I., Escandón, M.C., Fernández, L.G., Mustri, A. y Puga, I. (2000). La integración educativa en el aula regular. Principios, finalidades y estrategias. México: SEP, Fondo Mixto México-España.

García I. y Juárez, M. (2010). Condiciones médicas, familiares, escolares y sociales de niños y niñas con VIH en México. Psicología.com, 14(10), 1-14.

García, I. y Juárez, M. (2014). Promoción de una mayor adherencia terapéutica en niños con VIHISIDA mediante entrevista motivacional. Universitas Psychologica, 13(2), 651-660. Recuperado de https://revistas.javeriana.edu.co/index.php/revPsycho/issue/view/467

García, I., Viñas, X. y Rodríguez, C. (2013). Condición de vida de niños infectados por VIH/SIDA en un estado del centro de México. Rev Costarr Salud Pública, 2(22), 85-93.

Gil, J. (2013). Medición del nivel socioeconómico familiar en el alumnado de educación primaria. Revista de Educación, (362). https://dx.doi.org/10-4438/1988-592X-RE-2011-362-162

Grau, C. (2003). Necesidades educativas especiales derivadas de problemas crónicos de salud. En J.L. Gallego y E. Fernández (coords.), Enciclopedia de educación infantil (vol II, tema 66, pp. 781-804). Málaga: Aljibe. Recuperado de http://roderic.uv.es/handle/10550/40969

Grau, C. y González Ortiz, Ma. (2001). Atención educativa a las necesidades especiales derivadas de enfermedades crónicas y de larga duración. Recuperado de http://dialnet.unirioja.es/ servlet/articulo? $\operatorname{codig}_{0}=1203275$

Hernández, R., Fernández, C. y Baptista, P. (2010). Metodología de la investigación. México: McGraw-Hill Interamericana.

Hernández, E. y González, M.J. (2011). Modelo de ecuación estructural que evalúa las relaciones entre el estatus cultural y económico del estudiante y el logro educativo. Revista Electrónica de Investigación Educativa, 13(2), 188-203. Recuperado de http://redie.uabc.mx/redie/ article/ view/290/454

Jiménez, C. (1988). Condición socioeconómica de la familia y rendimientos escolares de los hijos al término de la E.G.B. Revista de Educación, (287), 55-70. Recuperado de http://www.mecd.gob.es/dctm/revista-de-educacion/articulosre287/re28703. pdf?documentId=0901e 72 b813c2ff9

Labin, A. y Taborda, A. (2014). Relación entre el nivel educativo materno y el desempeño en el WISC-IV: un estudio piloto. VI Congreso Internacional de Investigación y Práctica Profesional en Psicología, XXI Jornadas de Investigación, Décimo Encuentro de Investigadores en Psicología del Mercosur, Facultad de Psicología, Universidad de Buenos Aires, Buenos Aires. Recuperado de: https:/www.aacademica.org/000-035/795.pdf

Laboratorio Latinoamericano de Evaluación de la Calidad de la Educación. (2015). Tercer estudio regional comparativo y explicativo. UNESCO. Recuperado de https:/unesdoc.unesco.org/ ark:/48223/pf0000243980

Martínez, Y.J. y Ercikan, K. (2009). Chronic illnesses in Canadian children: What is the effect of illness on academic achievement, and anxiety and emotional disorders? Child: Care, Health and Development, 35(3), 391-401. https://dx.doi.org/10.1111/j.1365-2214.2008.00916.x

Morales, J.F.F., Vázquez, H.E.P. y Suárez, P.D. (2007). Hallazgos por imagen en los pacientes con VIH tratados en el Hospital Infantil de México Federico Gómez. Anales de Radiología, 6(1), 3-11. Mexico.

Morrissey, T.W., Hutchison, L. y Winsler, A. (2013, agosto 5). Family income, school attendance, and academic achievement in elementary school. Developmental Psychology. https://x.doi. org/10.1037/a0033848

Muñoz, J. (2012). Estudio del funcionamiento neurocognitivo en la infección por VIH en la era de las terapias antirretrovirales combinadas (tesis de doctorado no publicada). Universidad 
Autónoma de Barcelona. Recuperado de http://www.tdx.cat/bitstream/handle/10803/98409/ jammlde1.pdf?sequence $=1$

Nichols, S. (2013). Neuropsychology of HIV in children and adolescents. Psychology and AIDS Exchange Newsletter. Recuperado de https://www.apa.org/pi/aids/resources/ exchange/2013/01/neuropsychology-children

Pavía-Ruz N., Tovar-Larrea P., Muñoz-Hernández, R. (2003). Trastornos psicológicos en niños y adolescentes infectados perinatalmente por el VIH. Enf Infec y Microbiol, 23(4), 126-132.

Peña, C.M. (2002). Rendimiento escolar en Chile en establecimientos públicos y privados: ¿qué nos muestra la nueva evidencia? (tesis de maestría no publicada). Universidad de Chile. Recuperado de http://www.opech.cl/bibliografico/Doc_Financiamiento/ RendimientoEscolarEnChileEnEstablecimientosPublicosYPrivadosPena.pdf

Pérez-Cuevas, R., Pavía-Ruz, N., Pámanes-González, V., Torres-Castro, S., Castro-Ríos, A., Martínez-Ramírez, D., Lagunes-Toledo, A. y Muñoz-Hernández, O. (2009). Necesidades de atención social a la salud de los niños y adolescentes con VIH-SIDA; perspectivas del Hospital Infantil de México Federico Gómez. Bol Med Hosp Infant Mex, (66), 364-372. Recuperado de http://www.medigraphic.com/pdfs/bmhim/hi-2009/hi094j.pdf

Sánchez-Escobedo, P. (2006). Escala Wechsler de inteligencia para Niños-IV. Manual técnico. Versión estandarizada. México: El Manual Moderno.

Secretaría de Educación Pública. (2002). Programa Nacional de Fortalecimiento a la Educación Especial y de la Integración Educativa. México: SEP. Recuperado de https://www. educacionespecial.sep.gob.mx/pdf/publicaciones/prognal.pdf

Secretaría de Educación Pública. (2006). Orientaciones para el funcionamiento de los servicios de educación especial. México: SEP. Recuperado de https://www.educacionespecial.sep.gob.mx/ $\mathrm{pdf} /$ publicaciones/libromorado.pdf

Sentín, D. (2001). Influencia de los factores socioeconómicos en el rendimiento escolar internacional: hacia la igualdad de oportunidades educativas (informe técnico n. 1). Recuperado de http://eprints.ucm.es/6725/1/0101.pdf

UNAIDS. (2018). Knowledge is power. Know your status, know your viral load. Recuperado de http://www.unaids.org/sites/default/files/media_asset/jc2940_knowledge-is-power-report_ en.pdf

Usuga, X. (2012). Efectos adversos del tratamiento antirretroviral en niños infectados por el virus de la inmunodeficiencia humana. Infecto, 16(2), 122-127. https://dx.doi.org/10.1016/S01239392(12)70066-8

Vinaccia, S., Quiceno, J.M, Gaviria, A.M., Soto, A.M., Gil, M.D. y Ballester, R. (2007). Conductas sexuales de riesgo para la infección por vih/sida en adolescentes colombianos. Terapia Psicológica, 25(1), 39-50. Recuperado de https://scielo.conicyt.cl/scielo. php?pid=S0718-48082007000100003\&script=sci_arttext

\section{IotIIs}

${ }^{1}$ Los NoA asisten al hospital cada dos meses. Habitualmente viajan durante varias horas, y al llegar al hospital son sometidos a exámenes, de tal forma que tienen poco tiempo y energía disponible, por eso no se aplicaron todos los subtests esenciales de la WISC IV.

${ }^{2}$ Específicamente, se observa que, a mayor edad, las dificultades escolares resultan más evidentes. En este estudio, al término de la investigación, dos de las adolescentes de 14 años ya no asistían a la escuela, una por expulsión debido a peleas constantes con sus compañeros y la otra por embarazo, a quien la escuela sugirió que abandonara en lugar de apoyarla para que continuara sus estudios. 